differences are due to one or many factor-differences ; and when one remembers the initial difficulty in some of the most carefully-controlled experiments, even in Drosophila itself, of distinguishing between the effects of " nature" and " nurture," one can only feel that to lay down on such evidence, whether or not the inheritance of acquired characters has been operative, is a temerity the magnitude of which the author has probably not realised.

I have mentioned Dr. Annandale because I have just happened to read and be interested in his ecological observations: but similar instances abound. Per contra, as mentioned in a recent number of Nature, Dr. F. M. Chapman (Bull. American Museum of Natural History, vol. 48, I923, No. 9) has recently been attempting to utilise Mendelian conceptions in the taxonomy of birds. It is a useful exercise to compare the two methods. J. S. HuXLEY.

\section{New College,}

Oxford.

The Late Lord Rayleigh's Scientific Papers.

I HAVE at disposal separate copies of the majority of the scientific papers of my father, the late Lord Rayleigh. I shall be glad to entertain applications for any specified individual papers from scientific workers or students who may really need them. The stock of copies is of course limited, and I cannot promise to deal with the applications very promptly.

$$
\begin{gathered}
\text { Terling Place, Chelmsford, Essex, } \\
\text { April } 4 .
\end{gathered}
$$

The Continuous Spectrum of Hydrogen.

I NOTE with great interest in NATURE of February 23 a letter by Dr. F. Horton and Miss A. C. Davies referring to their paper in the Philosophical Magazine of November I923 entitled "Critical Electron Energies in Hydrogen." I wish to acknowledge their undoubted priority in the publication of the description of the continuous spectrum of hydrogen in the visible region. As this reference was buried in the text of this paper, it was overlooked in a rather cursory first reading of their work.

More recent work has fully confirmed the interpretation which Dr. Horton and Miss Davies give to our results in so far as it refers to the essential condition for the production of these spectra being a matter of voltage. We have reproduced all the effects described in our paper by variations of voltage between filament and plate. We cannot altogether agree with some of the inferences which they make as to the origin of this radiation, particularly with reference to their associating the minimum voltage for its production with $\mathrm{r} 2.6$ instead of 13.5 , and their interpretation that it is due to re-combination of neutral atoms into molecules.

One additional experimental fact needs emphasis, which is the following: After the lines of the Balmer series have ceased to be visible altogether and when the secondary spectrum also is almost entirely gone, there are two lines in the latter spectrum which remain very much more intense than all the rest of the secondary. These are in the orange at wavelengths approximately 6032 and 6021 . These lines also fade completely when the continuous spectrum is well developed, but their persistence after the rest of the secondary spectrum is virtually eliminated seems not to have been noted either in the experiments of Richardson and Tanaka, described in the issue of NATURE for February 9, or in those of Dr. Horton and Miss Davies. HARVEY B. Lemon.

The University of Chicago,

Ryerson Physical Laboratory, March 24

NO. 2842 , VOL. I I 3 ]
John Harrison.

I TRUST that you will allow an admirer of John Harrison to be a little indignant with your reviewer, "R. A. S.," of Lt.-Comdr. Gould's book (NATURE, March 22, p. 4I7). "To some he [Harrison] appears . . incurably clumsy. His taste for making clocks of wood, his complications, his retrograde inventions like the grasshopper escapement and the gridiron pendulum . . . stand to his debit." These are surely strange words for a man who (unless I misinterpret the initials) has been president of the Royal Astronomical Society, in the house of which stands that exquisite piece of mechanism, the Harrison clock, lovingly restored and enthusiastically described by Mr. E. T. Cottingham (Monthly Notices, R. A. S., lxx. 25, Nov. 1909). Harrison, it must be remembered, was the son of a carpenter, and brought up to that trade, whence his early clocks with wooden wheels. Harrison taught himself to be a clockmaker, and having a horror of friction, devised the delicately beautiful grasshopper escapement to be very nearly frictionless. Harrison invented the gridiron compensation, and applied it not only to pendulum-clocks but also to his first chronometers, to which Graham's mercury compensation was not suitable. Harrison was not alone among inventors in doing things at first in too complicated a way, learning simplicity by experience. It is common knowledge that most of Harrison's methods were almost immediately discarded -and something the same may be said of Isaac Newton-but it is extraordinary that any one who has seen the Harrison clock at the Royal Astronomical Society, or his fourth chronometer which won the prize, can call him incurably clumsy and retrograde!

"All Harrison's ideas," says your reviewer, "were of the nature of misdirections "; and this of the man who had the imagination and courage to tackle and eventually to solve the problem which was so important that the British Government offered 20,0ool for a solution, and so difficult that neither George Graham nor any other master of his craft-British or foreign-made any attempt to compete. The prize was offered in $17 \mathrm{r} 4$. Harrison first came to London about it in 1728 , finished his first machine in 1735 , his second in 1739 , his third in 1757 , and his fourth, the prize-winner, in 1759 . He received the last instalment of his reward in 1772 .

What were the whole profession of clock-makers doing all this time? They were doing practically nothing at all until the voyage of No. IV. to the West Indies in 1764 showed that the problem was solved; and then there was such an outburst of competition and invention that by I780 the chronometer had become almost standardised in its present form. "Opinions differ somewhat as to Harrison," says your reviewer, and proceeds to call him clumsy, retrograde, and misdirected! It is a sad piece of criticism. ARTHUR R. Hinks.

I TRUST that Mr. Hinks's energetic remarks will cause many readers to turn to Lt.-Comdr. Gould's fascinating volume. That author's admiration for Harrison is as great as could be wished; but in comparing him to Le Roy, he writes (on p. 9I) : "The difference in their machines is fundamentalHarrison built a wonderful house on the sand; but Le Roy dug down to the rock.'

With regard to the interesting Harrison clock in the rooms of the Royal Astronomical Society, which Mr. Hinks's energy and Mr. Cottingham's skill succeeded in setting in motion, the last few times I inquired about it I learned that it had returned to that state of repose that so well befits its years.
R. A. S. 